\title{
A contribuição da revista Comunicação \& Educação para a criação da Licenciatura em Educomunicação
}

Ismar de Oliveira Soares

Professor Titular do Departamento de Comunicações e Artes da ECA/USP. Coordenador do Núcleo de Comunicação e Educação (NCE)*.

Membro do Pontifício Conselho para as Comunicações Sociais (Vaticano 2001-2009). Coordenador do Projeto Mídias na Educação, do MEC, para o Estado de São Paulo.

E-mail: ismarolive@yahoo.com

Resumo: A apresentação busca contextualizar os artigos da presente edição de Comunicação \& Educação, classificando-os de acordo com as áreas de intervenção do campo da educomunicação. Com isso, deseja demonstrar a coerência do trabalho desenvolvido, ao longo dos últimos quinze anos, de um lado, pelos editores da revista e, de outro, pelo Departamento de Comunicações e Artes da USP, que obteve a aprovação, em novembro de 2009, de um curso de licenciatura voltado especificamente para a formação de educomunicadores. Fica demonstrado que a revista - uma das mais utilizadas como referencial bibliográfico em dissertações e teses do campo da comunicação - acabou por oferecer uma contribuição decisiva para a construção da nova e inédita proposta de formação de um profissional que será simultaneamente professor de comunicação e gestor de processos comunicacionais em espaços educativos.

Palavras-chave: educomunicação, intelectual orgânico coletivo, reflexão epistemológica, educação para a comunicação, gestão da comunicação.
Abstract: The preface contextualizes this issue's articles, classifying them according to their connections with the intervention areas of the educommunication field. With that, the author tries to show the consistency of the work developed along last 15 years, on one hand, by the magazine editors and, on the other, by USP's Department of Communication and Arts for the approval, in November of 2009, of an undergraduate course designed specifically for the formation of educommunicators. It is shown that the journal - that is the most utilized as bibliographic referential in the communication field thesis and dissertations - offered a decisive contribution for the construction of the new and inedited proposal that will result in the formation of a professional who will be simultaneously teacher of communication and communication processes manager in educational spaces.

Keywords: educommunication, collective organic intellectual, epistemological reflection, education for communication, management communication.
* O NCE localiza-se na Av. Prof. Lúcio Martins Rodrigues, 443 - bloco 9, sala 8 - Cidade Universitária - CEP 0558-900 - São Paulo/SP - Tel.: (11) 3091-4784. E-mail: nce@ edu.usp.br. 
comunicação \& educação • Ano XIV • Número 3 • set/dez 2009

Nos anos 1960 e 1970, circulava, com certa intensidade, em alguns meios acadêmicos e em boa parte das instituições do denominado Movimento Social, o conceito gramsciano de intelectual orgânico. Pensava-se, lato sensu, em indivíduos capazes de elaborar sínteses explicativas da realidade (conceito forte que chegou, até mesmo, a denominar uma revista de circulação nacional, distribuída pela editora Abril), garantindo sustentação teórico-metodológica para a mobilização de pessoas e instituições na busca de uma sociedade mais justa, a partir de uma cultura de resistência, fazendo frente às culturas hegemônicas. Pensava-se, na época, essencialmente, na luta pela democracia no País. Acreditava-se, enfim, no poder persuasório das ideias e na necessidade de se contar com a liderança de comunicadores comprometidos com as comunidades, capazes de motivar e conduzir programas e projetos na linha da comunicação participativa.

Com a redemocratização, a partir dos meados da década de 1980, o conceito perdeu uso corrente, sendo substituído, na prática, pela perspectiva mais coletivista da gestão de processos. O conceito de liderança mobilizadora foi, nesse sentido, transferido para as instituições, as organizações sociais. Daí a força adquirida pelas ONGs não apenas como substitutas eventuais do Estado, em determinados setores da vida social, mas como analistas de processos e condutoras de iniciativas pioneiras que, testadas, poderiam, até mesmo, ser admitidas como suficientemente legítimas para se transformarem em políticas públicas.

Devemos admitir: a revista Comunicação $\mathfrak{E}$ Educação surgiu justamente nesta perspectiva, no início dos anos 1990. A convicção de seus promotores residia na perspectiva de que uma abertura da área da comunicação para um diálogo fecundo com o setor educativo viria facilitar, ao longo de um período de tempo, a renovação de referenciais e procedimentais do modus operandi dos dois campos envolvidos no processo: o da comunicação e o da educação. Eminentemente acadêmica, pois nascia no espaço de uma universidade, a revista, escrita majoritariamente por pesquisadores, definiu como política editorial inegociável o diálogo com o professor do ensino básico. Isso implicava o estilo a ser adotado e a presença do professor como autor, no relato de suas experiências. A publicação assumia seu perfil de intelectual orgânico coletivo.

Sua editora de 1994 a 2005, Maria Aparecida Baccega, e, no mesmo período, coordenadora do Curso de Gestão de Processos Comunicacionais, instituição responsável, dentro da USP, pela nova iniciativa, ao responder à pergunta: "Por que a revista?", garantia ser intenção do projeto contribuir para a formação de profissionais capazes de:

a) usar os recursos da comunicação/cultura no processo ensino/aprendizagem;

b) saber planejar os processos de comunicação/cultura próprios do ambiente educacional;

c) desenvolver critérios e métodos para a análise das políticas e dos processos comunicacionais produzidos através da indústria cultural, dos chamados meios massivos como o cinema, a televisão, o rádio, os jornais, as revistas etc. 
$\mathrm{E}$ assim se sucedeu ininterruptamente nos últimos quinze anos: sem a pretensão do monopólio da verdade, a revista abriu-se ao mundo da interface entre a comunicação e a educação, abrigando conceitos e práticas. Entre os resultados alcançados registre-se, hoje, a Licenciatura em Educomunicação aprovada pelo Conselho Universitário da Universidade de São Paulo, em 17 de novembro de 2009. A Licenciatura Educomunicação é a primeira iniciativa deste gênero em nível nacional e mesmo internacional. O programa está vinculado à Escola de Comunicações e Artes (ECA), sendo administrado pelo Departamento de Comunicações e Artes. Entra em vigor em 2011, com 30 vagas no período noturno. Destina-se a preparar profissionais para atender a demandas provenientes tanto do campo da educação formal (magistério) quanto do campo das práticas comunicativas empreendidas pelos diversos setores da sociedade (mídia, organizações do terceiro setor, empresas e escolas). O espaço de atuação na docência é representado pelas disciplinas voltadas ao ensino da comunicação e de suas linguagens e tecnologias em cursos de nível médio, especialmente os profissionalizantes, assim como em cursos de educação a distância. Já o espaço de consultoria é representado pela atuação junto a projetos, em espaços governamentais ou empresariais, incluindo especialmente as empresas de comunicação social que tenham como objetivo a qualificação de seus processos e produtos para uma mais adequada prestação de serviços no âmbito da relação comunicação/educação. No caso, o educomunicador desempenha o papel de um assessor a serviço de ministérios, secretarias e departamentos de governo; colabora com a indústria cultural e o sistema de meios de comunicação, bem como participa de setores da iniciativa privada voltados para o desenvolvimento da expressão comunicativa em função da educação nas suas múltiplas formas. A grade curricular está estruturada de forma a abranger inicialmente disciplinas com fundamentos nas Ciências Humanas, permitindo aos alunos se apropriarem das teorias, tecnologias e práticas da comunicação. Seguem-se a parte específica da formação educomunicativa e os estudos de educação. Estágios supervisionados e um trabalho de conclusão de curso estão previstos na grade. O corpo docente - que conta com 19 professores doutores, especialistas em teorias, linguagens e gestão da comunicação; educação; teoria e crítica das artes e tecnologias da informação - assume as disciplinas e a direção do novo programa. Parcerias com o Museu de Arte Contemporânea (MAC), com a Faculdade de Educação (FE-USP) e com o sistema de meios de comunicação voltado à cultura e à educação garantem um diálogo mais consistente com o mundo da educação, das artes e do exercício profissional, necessário à formação do educomunicador.

\section{A EDUCOMUNICAÇÃO}

A revista nunca fez apologia do conceito da educomunicação, no sentido em que vem sendo defendido por um grupo de docentes e pesquisadores da Escola de Comunicações e Artes - ECA. Designamos a educomunicação como 
comunicação \& educação • Ano XIV • Número 3 • set/dez 2009

o conjunto das ações de caráter multidisciplinar voltadas ao planejamento e à implementação de práticas destinadas a criar e desenvolver ecossistemas comunicativos abertos e criativos nos distintos espaços educativos - dos não formais aos formais -, de forma a garantir condições de expressão a todos os membros das comunidades educativas, envolvendo, em igualdade de condições, gestores, comunicadores, ensinantes, receptores e educandos, especialmente crianças, adolescentes e jovens. Ou seja, a comunicação - promovida a partir da perspectiva da dialogicidade -, colocando-se como missão romper fundamentalmente o conceito de verticalidade de relações, possibilitando e ampliando, dessa forma, o uso da palavra.

A revista a entende, mais propriamente, como uma das possibilidades de interpretação do universo simbólico presente na interface entre a comunicação e a educação. No entanto, é inegável que Comunicação $\mathcal{E}$ Educação encontra-se entre os veículos especializados que mais têm colaborado para a explicitação do termo, contribuindo, dessa forma, decididamente, para levar o pensamento da ECA-USP ao sistema educativo e à juventude interessada em novos caminhos de formação universitária na interface entre a comunicação e a educação.

É importante reconhecer que dois projetos (o da revista e o da licenciatura) foram construídos a partir da teoria das mediações, segundo a qual - como garante Mauro Wilton de Souza - três direções marcam o sentido que assumem as práticas escolares no atual momento civilizatório:

a) a crise do modelo de sociedade derivado da modernidade capitalista que caracterizava a sociedade até meados do século XX;

b) a crise das novas relações que a sociedade estabelece com a tecnologia, de onde resulta a hegemonia do entretenimento sobre o saber, da imagem e do som sobre a escrita, configurando novos modos de ver a vida e o mundo, de se posicionar quanto às instituições formadoras, representadas social e culturalmente pela família, Igreja, escola, partidos etc; e, finalmente,

c) a crise da transformação da relação entre a escola e a comunicação ao longo da história recente, implicando práticas pedagógicas muitas vezes complexas e conflituosas.

É o que explica Souza, quando afirma:

As mediações socioculturais da contemporaneidade podem estar atuando de forma a ressignificar o lugar da escola, do professor e do aluno, de práticas e estratégias didático-pedagógicas, em um processo de lenta negociação, que já se torna perceptível em seus traços nos diversos conflitos que vemos emergir no ambiente escolar e educacional e que nos alertam para entender o caráter histórico e político do próprio sentido da educação ${ }^{1}$.

No contexto das três crises anunciadas, a resposta educomunicativa (e, em consequência, a licenciatura proposta) não encara apenas a escola como um dispositivo vitimado que necessita de transformações, mas volta-se expressamente para o conjunto dos processos que integram a comunicação no âmbito mais abrangente das mediações culturais, e que precisa ser repensado. 
A contribuição da revista Comunicação \& Educação • Ismar de O. Soares

O novo profissional a ser formado é convidado a trabalhar, nesse sentido, com o conceito de ecossistema comunicativo, identificado com os espaços de mediações, em que atuam, confrontam-se ou colaboram entre si, os sujeitos individuais e coletivos. No caso, o parâmetro é o grau do coeficiente comunicativo das práticas sociais, mensurados pela incidência comunicativa, ou seja, pela capacidade instalada de expressão comunicativa, garantida a todos os sujeitos sociais ${ }^{2}$.

De acordo com este foco, planejar os processos de comunicação/cultura no ambiente educacional, usar os recursos da comunicação/cultura no processo ensino/aprendizagem e desenvolver critérios e métodos para a análise das políticas e dos processos comunicacionais continuam a representar a essência do projeto da licenciatura da ECA-USP. Nesse sentido, o programa didático somente terá êxito se permitir que os alunos do novo curso construam referenciais teóricos e metodológicos suficientemente sólidos, de modo a garantir parâmetros para o exercício do planejamento e da gestão comunicativa.

A vantagem alcançada - fato que induz a pensar que este é o momento certo para se lançar um curso desta natureza - reside na constatação de que a própria sociedade civil já avançou em direção à disseminação das práticas educomunicativas. Trata-se de uma conquista amadurecida no ambiente alternativo (a educação popular, a comunicação alternativa e, até mesmo, a mídia-educação promovida por organizações sociais, entre tantas outras iniciativas que já renderam dissertações e teses de doutoramento) em busca de espaços de reconhecimento, garantindo-se, por exemplo, que o Ministério do Meio Ambiente defina um programa específico de Educomunicação Socioambiental e que, por outro lado, governos estaduais e municipais (como ocorreu nos Estados do Mato Grosso e da Bahia, assim como no Município de São Paulo) criem normas e programas estabelecendo a educomunicação como uma possível referência para seus parâmetros educativos formais ou complementares.

O que explicaria, por exemplo, experiências como as do Jornal da Tarde de veicular, semanalmente, aos domingos, entre abril de 2006 e novembro de 2007, um total de 80 páginas educomunicativas, elaboradas pelo Núcleo de Comunicação e Educação da USP, sobre temas transversais ao currículo do Ensino Fundamental; e, até mesmo, a proposta do Canal Futura de empreender a formação anual de 200 adolescentes e jovens para a produção videográfica, garantindo seu protagonismo nas comunidades onde residem, senão o entendimento de que a relação comunicação/educação já ganhou relevância no contexto das múltiplas mediações culturais?

\section{A CONTRIBUIÇÃO DA REVISTA PARA AS ÁREAS DE ATUAÇÃO DO NOVO CAMPO}

O sumário da revista permite ao leitor identificar as distintas seções e os conteúdos disponibilizados em cada uma delas. Nesta apresentação, pre-
2. Conceitos como "ecossistema comunicativo", "espaços de mediações", "coeficiente comunicativo", "incidência comunicativa" passam a ser usados nos textos produzidos especialmente pelas pesquisas do NCE-USP para descrever o contexto em que as ações educomunicativas ocorrem (ver especialmente: SOARES, Ismar de Oliveira. Comunicação/ Educação: a emergência de um novo campo e o perfil de seus profissionais. Contato, Brasília, ano 1, n. 1, pp. 19-74, jan./ mar. 1999). 
comunicação \& educação • Ano XIV • Número 3 • set/dez 2009

tendemos focar, explicitamente, a relação dos artigos no contexto do projeto da Licenciatura em Educomunicação, com a intenção de demonstrar como a revista tem contribuído para o esclarecimento de temas relacionados ao que o novo campo identifica com as áreas de intervenção ou áreas de atuação dos seus profissionais.

Inicialmente, queremos confirmar que os textos da presente edição de Comunicação E Educação efetivamente comprovam o que temos afirmado: a revista expõe, de forma didática, sua opção por uma integração entre a comunicação e a educação, em sua própria linha editorial. Assim, são contempladas as diversas áreas de intervenção do campo da educomunicação sobre as quais irá trabalhar a futura licenciatura, a saber: 1. A área da reflexão epistemológi$c a$, especificamente voltada para a pesquisa sobre a relação comunicação/ educação/cultura, identificando as justificativas teóricas das ações no novo campo, as tendências e procedimentos que configuram a interface em apreço; 2. A área da educação para a comunicação, focada na aplicação dos estudos de recepção às práticas de uma pedagogia que busque uma relação autônoma do público receptor com o sistema de meios de comunicação; 3. A área das mediações tecnológicas nos espaços educativos, que se preocupa com a presença das tecnologias como elemento interveniente nas mediações culturais que mobilizam a sociedade, com influências nos modos de perceber o mundo e de produzir cultura; 4. A área da pedagogia da comunicação, ligada a projetos, para garantir que as práticas educomunicativas sejam possíveis nos diferentes espaços educativos (o formal, o não formal e o informal), superando as resistências e as dificuldades próprias de um campo ainda em formação e que necessita dialogar com outras modalidades de se conceber as tecnologias e a comunicação nos espaços educativos; 5. A área da expressão comunicativa através das artes, identificando a prática social da imersão no fato artístico como forma de expressão criativa, assegurando o direito e a oportunidade de se fazer comunicação. 6. A área da gestão da comunicação nos espaços educativos, ocupada com os contextos em que o campo intervém, o que inclui as análises de conjuntura, o planejamento, a execução e avaliação de ações, bem como a implementação de programas que garantam espaço de atuação para as demais áreas de intervenção, assim como a coerência e a excelência do agir educomunicativo.

\section{OS ARTIGOS, SEGUNDO AS ÁREAS DE INTERVENÇÃO DO NOVO CAMPO}

1. A Área da reflexão epistemológica é brindada com um artigo de Maria Aparecida Baccega (Comunicação/educação e a construção de nova variável histórica). Para a autora, o campo comunicação/educação é um espaço privilegiado da atuação dos educadores, professores em particular, apresentando-o como lócus 
A contribuição da revista Comunicação \& Educação • Ismar de O. Soares

na formação dos sentidos sociais. Arrola outras características e mostra que comunicação/educação é mais que levar alunos a fazer telejornais, reproduzindo o que a comunicação tradicional estabelece como norma. Afirma, ao contrário, que as práticas comunicacionais no âmbito da interface em questão atuam no sentido de mudanças, permitindo que os sujeitos construam uma postura crítica fundamental diante da mídia e do mundo.

2. A área da educação para a comunicação é contemplada com textos voltados para a análise da produção da indústria cultural (cinema, televisão e representação teatral), com artigos de Christa Berger e Juliana Campos Chaves ( $A$ contribuição do cinema para a memória da ditadura brasileira), Maria Cristina Palma Mungioli (A função social da minissérie Grande Sertão: Veredas na construção de um sentido identitário de nação), Walter de Sousa (Piolin e Arrelia: entre o popular, o erudito e o massivo) e Maria Ignês Carlos Magno (Para além do exótico ou bélico: cinemas e histórias do país de Tagore e Jamal Malik).

$\mathrm{O}$ artigo de Berger e Chaves trabalha com os conceitos de memória, cinema e ditadura. Analisa uma amostra de 34 filmes produzidos no Brasil, com menções ao regime militar que vai de 1964 a 1980. Situa a questão da relação entre memória oficial e memórias subterrâneas, problematizando as funções da memória nos formatos da Indústria Cultural. Nesse contexto, o artigo relaciona a memória traumática brasileira ao circuito da memória mundializada.

O texto de Mungioli trata do sentido identitário do conceito de nação construído pela minissérie da Rede Globo intitulada Grande Sertão: Veredas. O referencial teórico e os procedimentos adotados pela autora possibilitam compreender a articulação entre gêneros literários, gêneros do discurso, gêneros televisuais e acabamento temático, numa perspectiva de construção histórica de um sentido de nação socialmente determinado. Neste artigo, a autora detém-se sobre um dos aspectos estudados em sua pesquisa de doutorado, analisando o que os discursos dos produtores e a imprensa especializada em televisão definiram como representando uma espécie de "caráter missionário" da minissérie. Neste quadro, o artigo procura entender a função social de uma produção midiática na construção de um sentido de nacionalidade por meio de discursos e imagens televisuais que pretendem mostrar o Brasil aos brasileiros.

O trabalho de Walter de Sousa relaciona o popular, o erudito e o massivo. Tendo como tema o circo-teatro, presente na paisagem urbana de São Paulo em todo o século XX, analisa a presença e a atuação de dois expoentes do circo brasileiro: Piolin e Arrelia, protagonistas de um espetáculo popular baseado na hibridização cultural.

Já a seção Videografia apresenta a contribuição de Maria Ignês Carlos Magno, que propõe para esta edição da revista reflexões a partir do filme Quem quer ser um milionário?, de Danny Boyle, com roteiro de Simon Beaufoy, 
comunicação \& educação • Ano XIV • Número 3 • set/dez 2009

adaptado da novela de Vikas Swarup, Q \& A. O objetivo é recuperar aspectos da história e da cultura indiana a partir da história dos seus cinemas.

Em seu conjunto, os referidos artigos contribuem para definir parâmetros para um adequado processo de educação para a comunicação.

3. A área das mediações tecnológicas nos espaços educativos é contemplada pelo artigo da seção Crítica, de Vander Casaqui (Espacialidades, consumo e trabalho pelos olhos de Mr. Hulot: uma análise de Playtime, de Jacques Tati), em que faz uma reflexão erudita do filme Playtime, de Jacques Tati (1967), a partir do qual o autor trata das questões do consumo, do mundo do trabalho e da comunicação humana mediada pela arquitetura contemporânea e pelos aparatos tecnológicos. O quadro teórico é baseado nos estudos de Walter Benjamin sobre "Paris e as Exposições Universais", nas reflexões de Beatriz Sarlo a respeito das espacialidades do consumo e na obra de Wolfgang Fritz Haug sobre as estratégias estéticas do mundo do trabalho nesses espaços.

Existe outro texto que aborda o tema das mediações tecnológicas, contemplando a relação entre a TV e seu público, no específico momento em que a digitalização se converte num assunto que perpassa a área da gestão, para a qual definimos remetê-lo.

4. A área da pedagogia da comunicaşão é contemplada permanentemente pela revista com as Atividades em Sala de Aula, propostas por Ruth Ribas Itacarambi. Trata-se de um exercício de leitura da própria revista e da aplicação dos conceitos e propostas veiculados ao cotidiano da didática.

Seguindo caminho inverso, da sala de aula vem outra contribuição, agora oferecida pelas professoras Cláudia Regina Lahni e Fernanda Coelho, que apresentam aos leitores um relato de experiência (A comunicação a serviço da cidadania e identidade de adolescentes). Na verdade, trata-se de uma aplicação da pedagogia de projetos para garantir que crianças e adolescentes se apropriem das linguagens dos meios e de suas tecnologias.

No caso do presente relato, as autoras fazem uma breve análise histórica da situação da juventude no Brasil, apontando a educomunicação como facilitadora da relação entre professores e alunos. Entendem que o conceito é portador de uma metodologia que facilita o uso das linguagens da comunicação, em especial do rádio, como instrumento favorecedor do exercício da cidadania dos jovens, principalmente das classes populares. $\mathrm{O}$ relato apresenta algumas iniciativas como tecnologias para se chegar a tal objetivo. É o caso do projeto Jornal $e$ Rádio no UFJF: Território de Oportunidades, de cujos participantes foi realizada uma pesquisa quantitativa e qualitativa de resultados.

5. A área da expressão comunicativa através das artes é representada pelo espaço das seções Entrevista e Depoimento da revista. Trazem dois relatos de agentes culturais que sintetizam o perfil do profissional que a nova licenciatura define como o educomunicador. Fala-se de um compositor, cantor e bailarino popular, Antônio Carlos Nóbrega, e de uma professora, jornalista e escritora, Fanny Abramovich. Ambos têm um denominador comum: um trabalho criativo 
contextualizado na relação entre comunicação/arte/educação, embasado numa ética de compromisso com a cultura brasileira.

Antônio Carlos Nóbrega representa a área educomunicativa identificada com a expressão comunicativa através das artes. Em entrevista para a articulista Juliana Winkel (Brincante: o encontro do popular e do erudito a serviço da cultura $e$ da educação), relata que se viu diante de um mundo novo quando, aos 18 anos, teve pela primeira vez contato com as manifestações de música, arte e dança populares. Estimulado pelo trabalho junto ao Movimento Armorial, organizado por Ariano Suassuna na década de 1970, o jovem músico de classe média descobriu novas formas de expressão artística com o povo do Nordeste. A herança desse trabalho carregaria pela vida afora - especialmente a partir de 1976, quando o espetáculo A Bandeira do Divino marcaria o início de sua carreira solo, levando sempre a mistura da técnica e da expressão eruditas com a cultura das tradições populares brasileiras. A experiência sobre os palcos faria com que Antônio e sua esposa, Rosane Almeida, expandissem as atividades para outras esferas artísticas e educativas. Em 1992, nasce o Teatro Brincante, que, mais tarde, se tornaria Instituto Brincante, oferecendo cursos para educadores e a comunidade, relacionados às técnicas usadas nos espetáculos. Já em 2009, Antônio Nóbrega se lança a mais um desafio: sintetizar sua paixão pela dança e toda a multidisciplinaridade que acompanha seu trabalho em um único espetáculo, assumindo, sobre o palco, também a função de educador, ou educomunicador.

Em seu depoimento (A única função do educador é pôr a criança na rua, no mundo), Fanny Abramovich se apresenta como uma profissional que soube transitar com tranquilidade e eficiência entre os mundos da indústria cultural e da educação formal, conciliando suas múltiplas funções no âmbito da convergência entre a comunicação e a educação. Pedagoga formada pela Universidade de São Paulo, jornalista e escritora, Fanny dedicou-se especialmente a escrever livros tanto para crianças quanto para jovens e adultos, mexendo especialmente com criatividade-educação. Aproximou-se, para tanto, do mundo dos brinquedos, dos discos e do teatro. Fez o mesmo tipo de trabalho na televisão, bem como colaborou intensamente com vários jornais e revistas. Atuou em consultoria para projetos especialmente criados para crianças e jovens, na área do teatro, da literatura e da educação. Seu depoimento identifica parâmetros para o trabalho do profissional a ser formado pela nova licenciatura.

6. A área da gestão da comunicação nos espaços educativos (aqui, associada à área das mediações tecnológicas) conta com a contribuição dos jornalistas Vanessa Vantine e Ademir Ribeiro, que refletem sobre a presença das tecnologias num momento singular das transformações pelas quais passa o sistema de comunicação do País. Trata-se do artigo TV Vanguarda e os desafios da migração do analógico ao digital, com foco na convergência das mídias, que prevê a mudança em curso de sistemas analógicos para digitais, em decorrência da implantação da TV Digital interativa no Brasil. Nesse cenário, os autores não apenas analisam a cultura digital, mas também se detêm 
comunicação \& educação • Ano XIV • Número 3 • set/dez 2009

na recente geração que tem como referência a nova realidade. O objeto de estudo do artigo é a afiliada da Rede Globo em São José dos Campos e região, no Vale do Paraíba, interior de São Paulo. O trabalho apresenta propostas para que a emissora não apenas faça as adequações necessárias à Era Digital, mas também discuta sobre o futuro da produção televisiva com seus telespectadores que, de acordo com as suas pesquisas, querem, cada vez mais, interagir.

\section{OUTROS TEMAS}

Não acreditamos que as seis áreas de intervenção apresentadas esgotem as possibilidades de classificação do agir educomunicativo. Podemos trabalhar também a partir de conceitos-chave, como é o caso do termo ecossistema comunicativo. É por onde caminha o artigo internacional, de Graça dos Santos, que traz um tema que tem a ver, até certo ponto, com a gestão da comunicação em espaços educativos, que é o caso dos internatos. O artigo trata da função educadora da Igreja no contexto histórico de sociedades fechadas. No caso específico do artigo $O$ seminário, escola dos pobres, em Manhã submersa (1953), de Vergílio Ferreira, a autora apresenta uma síntese do processo educativo engendrado durante a ditadura de Salazar, em Portugal, na primeira metade do século XX. Ela constata que, no momento em que Salazar toma o poder como presidente do conselho (1932), o seminário já era uma solução de sobrevivência e de escolarização para os jovens garotos saídos de meios pobres, o que era o caso, por sinal, do chefe do Estado Novo, assim como do próprio autor do romance, Vergílio Ferreira. Manhã submersa (Matin Perdu), que obteve o Prix Fémina 1990, na França, narra, dessa forma, o ecossistema comunicativo que encerra o destino de António dos Santos Lopes, colocando em debate a escola, a religião e, por consequência, a laicização durante o Estado Novo de Salazar.

A revista não descuida da forma literária, mantendo espaço para a poesia (A poesia de Manuel de Barros: entre o regional e o universal), comentada por Adilson Citelli e Cristine Vargas, que abordam como a dimensão super-regional de Manoel de Barros se apresenta como superação do conflito campo versus cidade. São mantidos os boletins bibliográficos (Bibliografia sobre telenovela brasileira, com Maria Immacolata Vassallo de Lopes; Bibliografia sobre comunicação e educação, com Ismar de Oliveira Soares, e Enderȩ̧os úteis na internet, com Juliana Winkel).

E nessa diversidade criativa, há - na seção Serviço - a linguagem universal do esporte, apresentando um museu localizado no Estádio do Pacaembu, em São Paulo (SP), cujos conteúdos são comunicados ao público sob a forma de exposições, palestras, cursos, oficinas, eventos, publicações e uma diversidade de ações educativas intra e extramuros. Trata-se do texto Museu do Futebol: o Brasil com emoção, história e diversão, de Laura Avancine. 
A contribuição da revista Comunicação \& Educação • Ismar de O. Soares

\section{COMUNICAÇÃO \& EDUCAÇÃO E A LICENCIATURA}

Ao chegar à plenitude de seus 15 anos, a revista Comunicação $\mathcal{E}$ Educação e o Departamento de Comunicações e Artes da ECA/USP, responsável pelo projeto da Licenciatura em Educomunicação, têm muito a comemorar, especialmente a coerência demonstrada pelos editores da publicação e pelos sucessivos chefes do CCA, ao longo desta década e meia, no sentido de manterem-se fiéis ao projeto pensado e articulado já no início de 1990.

É importante ressaltar que essa coerência foi sentida também pelo público leitor, que acabou por fazer uso constante da revista em seus estudos e na preparação de suas dissertações e teses. Foi o que constatou a pesquisa $O$ campo da comunicação e suas referências: experimento metodológico para a produção de indicadores bibliométricos (2009), coordenada por Margarida M. Krunsch, ao identificar a revista Comunicação $\mathcal{E}$ Educação como a mais referendada, dentre as revistas brasileiras, em pesquisas acadêmicas no campo da comunicação em 2004, mantendo-se entre as três primeiras até o presente momento.

Uma boa leitura para todos! 


\section{बृ}
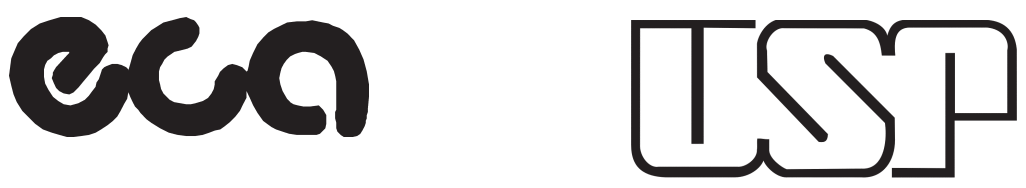

\section{ESPECIALIZAÇÃO LATO SENSU Gestão da Comunicação}

gestor da comunicação planeja e executa projetos de comunicação em empresas privadas, instituições públicas ou movimentos comunitários, nas áreas educacional, empresarial ou artístico-cultural.

- Capacitação do aluno para elaborar, implantar, avaliar e reestruturar projetos de comunicação/cultura.

- Integração teórico-prática da área de comunicação com o mercado de trabalho.

- Formação humanística e profissional sólidas, baseada na inter-relação comunicação/cultura/artes.

- Qualificação do profissional, preparando-o para compreender o mercado emergente, em constante transformação, e agir sobre ele.
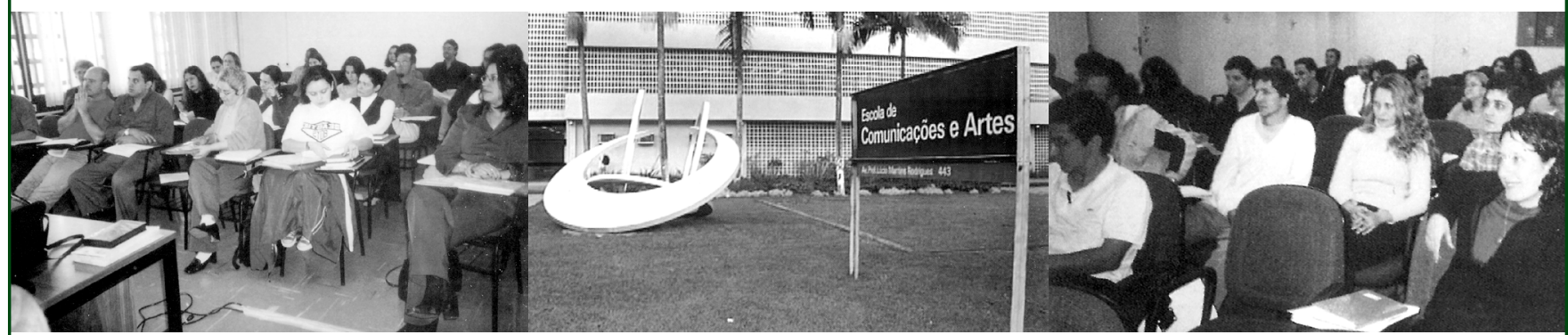

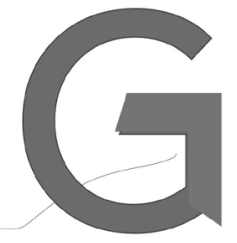

Gestão da

Comunicação Especializaçăo lato sensu

CCA - ECA - USP
Duração: três semestres

Pré-requisito: formação superior (qualquer área)

Seleção: prova escrita, entrevista e plano de estudo

Ingresso semestral: $1^{\circ}$ semestre: turma com aulas às sextas-feiras e aos sábados 2 - semestre: turma com aulas de segunda a quarta-feira

Informações: ECA/USP: 3091-4063/4341/4326 - e-mail: gestcom@edu.usp.br www.eca.usp.br/gestcom 